\title{
Psychosocial Workplace Hazards and Workers' Health in Factory Sector
}

\author{
Shiau Wei Chan ${ }^{1, ~}$, Tasmin, R. ${ }^{1}$, A. H. Nor Aziati ${ }^{1}$, Raja Zuraidah Rasi ${ }^{1}$, \\ Fadillah Binti Ismail ${ }^{1}$, Rumaizah Ruslan ${ }^{1}$, Ramlan R. ${ }^{1}$, Nur Syereena \\ Nojumuddin ${ }^{1}$, M.F. Ahmad ${ }^{1}$, Siti Sarah Omar', Izzuddin Zaman², Muhamad \\ Fuad Anuar ${ }^{1}$
}

\author{
${ }^{1}$ Department of Production and Operation Management, Faculty of Technology Management and Business, Universiti \\ Tun Hussein Onn Malaysia, Batu Pahat 86400, MALAYSIA. \\ ${ }^{2}$ Department of Mechanical Engineering, Faculty of Mechanical and Manufacturing Engineering, Universiti Tun \\ Hussein Onn Malaysia, Batu Pahat 86400, MALAYSIA.
}

\section{Received 00 August 2018; Accepted 01 August 2018; Available online 30 October 2018}

\begin{abstract}
Nowadays, issues on psychosocial workplace hazards have become a hot topic. However, only a small amount of research has been conducted in Malaysia. The purpose of this study is to determine the relationship between psychosocial workplace hazards and workers' health which is measured using Body Mass Index (BMI) as well as mental health. Two research hypotheses related to psychosocial workplace hazards, i.e. Body Mass Index (BMI) and mental health were examined. In this study, 105 workers were selected randomly from factories located in Klang, Selangor, and questionnaires were distributed to them. The result revealed that there is a significant relationship between psychosocial workplace hazards and BMI, while there is no significant relationship between psychosocial workplace hazards and mental health. This study serves as a guideline for organisations concerning the relationship between psychosocial workplace hazards with workers' health.
\end{abstract}

Keywords: Psychosocial workplace hazards, Body Mass Index, mental health, factory sector

\section{Introduction}

Earlier studies have revealed that psychosocial workplace hazards may cause a huge impact on workers' health [1]. Psychosocial workplace hazards are defined as the aspects of job content, work organisation and management and of social and organisational conditions which have the potential for physical and psychological harm [2]. The Malaysian National Health and Morbidity Survey which conducted a survey on Non-Communicable Diseases (NCD) risk factors stated that $27.2 \%$ or 4.4 million adults in Malaysia are obese in only a year [3]. Almost $45 \%$ of the Malaysian population are rated as heavyweight, followed by South Korea, Pakistan and China. In Malaysia, a survey was conducted on 1,612 females working in 10 large electronics assembly factories. More than $78 \%$ of the subjects were Malay and about 71 percent of them were below 35 years old. More than half of the women $(57.6 \%)$ worked three shifts, rotating every seven to ten days. Data were obtained using self-administered questionnaires. The results revealed that working in rotating shifts including nights and long working hours is significantly associated with being overweight (as defined by Body the Mass Index)[4].
Malaysia as the one of the fastest developing countries in Southeast Asia may need to keep the pace of development to compete with other countries in the Southeast Asia region. In 2011, the GDP of Malaysia was about $\$ 450$ billion - the third-largest economy in ASEAN, and 29th-largest in the world [5]. This situation mostly affects companies and institutions in Malaysia. The increased workload may cause psychosocial workplace hazards to happen. The huge amount of workload has been shown to have increased potential in compromising workplace safety outcomes [6]. Health problems will be affected by psychological stress, but studies have also shown that psychosocial hazards cannot give impact towards our bodies directly [7]. Studies which have inspected the connection between physical hazards and humans' well-being have the tendency to be gathered by particular physical hazards. Conversely, psychosocial hazards will be gathered by the health result [7]. Thus, it is crucial to figure out how the overall health of workers can be affected by psychosocial workplace hazards.

There is a deficiency in studies which test how psychosocial hazards can affect physical health [7]. In Malaysia currently, there are only a few studies that have been conducted. Most of the studies that have been conducted relate physical workplace hazards with workers' health compared to psychosocial workplace 
hazards on workers' health by comparing the accident rate. Hence, in this study, the researcher aims to identify the relationship between psychosocial workplace hazards and workers' Body Mass Index (BMI) as well as the relationship between psychosocial workplace hazards and workers' mental health in the factory sector.

\section{Literature Review}

\subsection{Psychosocial Workplace Hazards}

Nowadays, psychosocial workplace hazards have become a hot issue for the working population. Psychosocial workplace hazards are defined as parts of occupation substance, work hierarchical administration, environments, social, and authoritative conditions which can bring about mental or physical mischief [2]. Both psychological and physical health can be affected by workplace hazards [8]. From this statement, we can assume that workplace hazards can give some impact towards humans' body from both the outside and inside. Reports on bullying and harassment have shown figures that have almost doubled since 2008. Statistics show that there is a rise in bullying and harassment at the workplace from $20 \%$ to $37 \%$ in the year 2010 [9].

Larger workplaces are frequently connected with issues of psychosocial workplace hazards [7]. Psychosocial hazards can give impact towards our bodies physically and mentally, whether through direct or indirect stress. Most previous studies have highlighted the non-direct, stress-related psychosocial hazards on workers' health [2]. Basically, psychosocial hazards are related to an organisation's environment and role, workers' career development, workers' relationships at the workplace, work designation, amount of work assigned, and the ways work should be executed [2].

Basically, work gives some benefits to humans' mental health and personal comfort. It provides a person with structure and function, together with a sense of identity. It also provides opportunities for the person to enhance and use his/her knowledge and specialty to form social interactions and boost his/her confidence level. However, there are some elements in the work area that may have bad effects towards humans' mental and physical health. Organisations and other personal matters have been shown to be factors that give rise to issues of psychosocial workplace hazards. The main problems that have been identified are bad work schedules, lack of connections' quality, and low communication between coworkers. Mental health related to the workplace should be assessed, analysed and classified as important as it may pose risks to workers' safety. Organisations or companies should focus on this matter thoroughly and create better rules [10].

In consideration of job demands, it is crucial to find the psychosocial hazards caused by excessive amount of work, such as if the workers do experience a good working environment or have gone through decent training and possess high skills and knowledge. Workers that work above their limits may be at risk of experiencing stress issues. Other than that, if workers suffer long-term stress, they may suffer from serious mental health problems which may then affect their hearts and maybe some other parts of their body. Organisations will also suffer from some bad consequences such as workers' bad performance and slow production. Workers also cannot work efficiently if they come to the workplace in a sick state. Records of accidents and injuries at the workplace may also rise. Early retirement statistics will also increase due to the stress coming from the working environment [11].

\subsection{Obesity and Overweight}

Understanding how obesity and overweight give impacts towards humans' body and how the environment and individual elements can affect obesity and overweight is very important $[7,12]$. According to the World Health Organisation (WHO) [13], obesity and overweight are defined as the redundancy of fat that is concentrated together and can cause bad impacts towards humans' health. The WHO [13] also stated that adults are classified as overweight if they have a Body Mass Index (BMI) which is greater than or equal to 25 , while adults are classified as obese if they have a Body Mass Index (BMI) which is greater than or equal to 30 . The method to calculate the Body Mass Index (BMI) is by dividing a person's weight in kilograms by the multiplication product of the person's height in meters [14].

Basically, there are many factors that can cause a person to become overweight or obese. Most of the factors are related to the person itself. Based on the WHO [13], the main reason a person becomes overweight or obese is the difference between the amount of calories taken and the calories that are used. There are also some other important aspects that may become reasons of people becoming overweight or obese. Practicing only small amounts of physical activity has also been shown to have a huge impact on humans' weight.

There also factors that may cause the practice of only a small amount of physical activity, such as different types of working conditions and environments, the changing of vehicles to go to the work, and the increasing amount of social processes between people [13]. Obesity is linked with various types of diseases such as diabetes, coronary heart diseases, some types of cancer such as breast cancer and bowel cancer, and lastly stroke [15].

\subsection{Mental health}

According to the WHO [16], mental health is defined as the condition of complete physical, mental and social health and is no more than the non-appearance of disease and mental weakness. There are three different indicators of mental health according to the Centre Disease Control (CDC) [17]. The first indicator is emotional well-being. This indicator is related to life satisfaction, peacefulness and happiness. The next indicator is psychological wellbeing. This indicator includes factors of selfacknowledgment, self-awareness, openness to new encounters, confidence, reason in life, control of one's 
condition, a deep sense of being, self-course, and positive connections. The last indicator is social well-being. It includes social acknowledgment, convictions in the capability of individuals, individual self-esteem and a sense of group [17].

Based on the Mayo Clinic Staff [18], mental illness is defined as a huge scale of mental health conditions and a sickness that can have an impact towards humans' behaviour, thoughts and emotions. Examples of mental illnesses include depression, anxiety disorders, schizophrenia, eating disorders and addictive behaviours [18]. Work can add to the advancement of mental sickness through poor working environments and workassociated issues [19]. The workplace plays a huge part in causing mental health problems among the working population. There is proof which demonstrates that the poor association and administration of work assumes a huge part in the presence of emotional wellness issues $[20,21]$. In other research, psychosocial issues (for example, the absence of employment control, low choice scope, low ability prudence and work strain) have been observed to be related to the danger of discouragement, weaknesses in working, nervousness, trouble, weariness, work disappointment, burnout and absence due to sickness[20].

\subsection{Previous Studies}

Over the years, numerous studies have been undertaken to explore the relationship between psychosocial workplace hazards and Body Mass Index (BMI). One such study was conducted by Schulte et al. [22] to determine the relationship between long working hours with Body Mass Index (BMI). In the study, the researchers distributed questionnaires among Canadian workers and the result from the correlation analysis showed that workers who work more than 35 hours a week had an odds ratio of 1.4 for being overweight.

A more recent study by Ghimire [23] was conducted on the relationship between psychosocial workplace hazards and BMI. He distributed questionnaires to 2,118 Finnish workers and the results indicated that $8.9 \%$ of the workers have high Body Mass Index (BMI). Stanyar's [7] study was also conducted to identify the relationship between psychosocial workplace hazards and Body Mass Index. The instrument used was the questionnaire which was distributed to 16,651 civil servant workers. The results showed that there is a negative relation between psychosocial workplace hazards and Body Mass Index (BMI).

Another study conducted by Hafner et al. [24] compared the effect of psychosocial workplace hazards on males and females' BMI. Questionnaires were distributed to 21,882 British employees. The results show that 17.8 per cent of men and 18.3 per cent of women who were currently employed have a self-reported BMI of larger than 30, which is classified as obese. Arlinghaus et al. [25] conducted a survey on the relationship between long working hours and psychological stress with Body Mass Index (BMI). A set of questionnaires were distributed to 89,366 workers, and the results of the study showed that there exists a relationship between high amounts of working hours, high psychosocial stress and high Body Mass Index (BMI).

Many studies have been done to identify the relationship between psychosocial workplace hazards with mental health. One of the studies was conducted by Kortum [26]. The purpose of the study is to find the relationship between depression and anxiety with workers' general mental health. The researcher distributed questionnaires to 120 workers, and the responses obtained showed issues related to overall mental health problems such as serious suicide cases, and mental health problems including unhappiness.

Another study by Leka \& Jain [1] was aimed to test the relationship between psychological stress and mental health. The instrument used was questionnaires. The questionnaires were distributed to 8,800 workers and the results showed that from participants who were still working, $23.0 \%$ had experienced several periods of work stress compared with $17 \cdot 9 \%$ of controls, and $10 \cdot 0 \%$ experienced permanent work $17 \cdot 9 \%$ of controls, and $10 \bullet 0 \%$ experienced permanent work stress during the previous year versus $5 \bullet 0 \%$ of controls.

Other than that, a study by Lundqvist [27] on the relationship between psychosocial workplace hazards and mental health which utilised questionnaires found that there is a positive relationship between psychosocial workplace hazards with mental health. Unfortunately, another study by Stanyar [7] with the same purpose showed different results. Questionnaires were distributed to 16,651 civil servant workers to study the same relationship. The result demonstrated that psychosocial workplace hazards negatively impact general mental health.

\section{Methodology \\ 3.1 Research Design}

This study employed the quantitative method which uses objective measurements and mathematical, statistical or numerical analysis of data assembled together by surveys and questionnaires or by utilising already published statistical data using computational methods [28]. This study used the quantitative research method because it is suitable to be used to accomplish the objective of this research. For this research, the researcher used two types of data resources which are primary data and secondary data. Primary data is information that are collected for the purposes of this research project, while secondary data is data that have already been collected and are readily published in different resources [29]. In this research, primary data was collected through the distribution of questionnaires to the chosen respondents. Secondary data for this research were collected from journals and articles from both websites and online libraries such as Emerald Insight, Science Direct, Research Gate and much more. Then, the data were analysed quantitatively using SPSS software.

\subsection{Respondents}


A sampling is needed to conduct this research since it is very difficult to study the whole population. The sample size for this study was determined using Krejcie and Morgan's table [30]. The targeted population for this research is 300 workers from factories located in Klang, Selangor; therefore, the sample size was calculated to be 169 respondents. This research used random sampling in which each unit in the population has an equal chance of being selected. However, only 105 questionnaires were managed to be collected with a response rate of $62.1 \%$. This was because of many respondents reluctant to fill in the questionnaire.

\subsection{Instrumentation}

This research was carried out using the questionnaire as an instrument. In this survey, the questionnaire was used as a tool for gathering data. There were four sections included in the questionnaire, i.e. Section A, Section B, Section C1 and Section C2. For Section A, the content was about the demographic profile of the respondents. Meanwhile for Section B, questions included were on psychosocial workplace hazards and answers employed the use of a 7-point Likert scale which ranging from "strongly disagree" to "strongly agree". The next section was Section C1 which consisted of questions on respondents' current height and weight, which were then used to calculate their Body Mass Index (BMI). The last section which was Section C2 contained questions on respondents' mental health which were measured using a 7-point Likert scale. Questions from this section were taken from the General Mental Health-12 Questionnaire.

Pre-testing was conducted on 30 workers from the same sample. Any adjustment and improvement to the questionnaire was done after the pre-testing. The completed and edited questionnaire was then distributed to the targeted samples. The Cronbach Alpha value for the pre-test for all variables was 0.794 , which shows that the instrument is an acceptable and valid questionnaire [31].

\subsection{Data Analysis}

Statistical Package for Social Science (SPSS) was used to analyse the data that had been collected. SPSS is a software package used for statistical analysis which produces accurate results either in the form of tables or graphical charts. Descriptive analysis was used to calculate the frequency, average number, percentage, mean score and standard deviation. By using the data generated from data analysis, the demographic characteristics of factory employees in this study was identified. The correlation analysis, the Cramer' V correlation and Spearman correlation were used to examine the relationship between the independent variable and dependent variable. Cramer' V was utilized to identify the relationship between psychosocial workplace hazards and workers' Body Mass Index (BMI) due to one of the variables (BMI) is the nominal data. Meanwhile, the Spearman correlation was employed to determine the relationship between psychosocial workplace hazards and workers' mental health because the data were not normally distributed.

\section{Results and Discussion}

\subsection{Relationship between psychosocial workplace hazards and body mass index (BMI)}

Table 1 shows the significance value of the relationship between psychosocial workplace hazards and Body Mass Index (BMI) which was recorded at $0.000<$ 0.05 . Thus, $\mathrm{H} 0$ is rejected because the significance value is less than 0.05. So, there is significant correlation between these two variables. The value of Cramer V shows that there is strong relationship between psychosocial workplace hazards and Body Mass Index. From the analysis, we can conclude that the correlations were strong and positive. This is an agreement with the findings of Arlinghaus et al. [25] which showed that there is the existence of relationship between long working hours, high psychological distress, and high BMI.

Table 1: Cramer' V Correlation

\begin{tabular}{|c|c|c|c|}
\hline Items & Cramer V & $\begin{array}{c}\text { Approx } \\
\text { Sig }\end{array}$ & $\begin{array}{c}\text { Sig or } \\
\text { not }\end{array}$ \\
\hline $\begin{array}{c}\text { Psychosocial } \\
\text { hazards*BMI }\end{array}$ & 0.910 & 0.000 & Sig \\
\hline
\end{tabular}

\subsection{Relationship between psychosocial workplace hazards and mental health}

Table 2 demonstrates the result of the Spearman correlation. It reveals that there is no significant relationship between these two variables. Table 4.14 shows that the significant value of psychosocial workplace hazards towards mental health recorded was $0.087>0.05$. Thus, H0 is accepted because the significance value is more than 0.05 . Thus, there is no statistically significant correlation between these two variables. The value of the correlation coefficient shows that there is a weak but positive relationship between psychosocial workplace hazards and mental health. This analysis is related with the findings of Stanyar [7] who stated that psychosocial workplace hazards is negatively related to general mental health.

Table 2: Spearman Correlation

\begin{tabular}{|c|c|c|c|}
\hline Items & Spearman & $\begin{array}{c}\text { Approx } \\
\text { Sig }\end{array}$ & $\begin{array}{c}\text { Sig or } \\
\text { not }\end{array}$ \\
\hline $\begin{array}{c}\text { Psychosocial } \\
\text { hazards*Mental } \\
\text { Health }\end{array}$ & 0.168 & 0.087 & Not \\
\hline
\end{tabular}

\section{Conclusion}

The study demonstrates that only Body Mass Index (BMI) is correlated with psychosocial workplace hazards, while mental health is not significantly correlated with psychosocial workplace hazards. The design of this study and its findings contribute to an improved understanding 
of psychosocial workplace hazards and their relation to Body Mass Index (BMI) and mental health. Future research should be conducted in different contexts such as in different industries and also consider the mediating role of elements such as job scope on the studied relationship.

\section{Acknowledgement}

This work was funded by Universiti Tun Hussein Onn Malaysia (UTHM) under Grant No. U431.

\section{References}

[1] Leka, S., \& Jain, A., Health impact of psychosocial hazards at work: an overview, (2010), Aditya Jain. Geneva: World Health Organization.

[2] Cox, T., Stress research and stress Management: Putting theory to work, (1993), Nottingham University, HSE Contract Research Report No. 61/1993, 34-35.

[3] Tsioufis, K. P., Dimitriadis, K., Koutra, E., Kasiakogias, A., Kordalis, A., Tsiachris, D., Mattson, M. P., National health and morbidity survey 2011. Clinical Chemistry, Volume 51(6), (2015), pp. 931938.

[4] Amani, R., Nutr, R., \& Gill, T., Shiftworking, nutrition and obesity: implications for workforce health- a systematic review. Asia Pacific Journal of Clinical Nutrition, Volume 22(4), (2013), pp. 698708.

[5] Brown, J., Southeast Asia: Region on the Rise Inbound Logistics, (2013), Retrieved on March 4, 2017 ,

from http://www.inboundlogistics.com/cms/article/southea stasia-region-on-the-rise/

[6] Turner, N., Chmiel, N., Hershcovis, M. S., \& Walls, M., Life on the line: Job demands, perceived coworker support for safety, and hazardous work events. Journal Occupational Health Psychology, Volume 15(4), (2010), pp. 482-493.

[7] Stanyar, K. R., Impact of physical and psychosocial workplace hazards on employee health: An irish tale of civil servant workers, (2015), Dissertation Abstracts International: Section B: The Sciences and Engineering, 75(10-B(E)).

[8] World Health Organisation (WHO), Occupational health: A manual for primary health care workers. World Health Organization, (2001), pp. 173.

[9] Wilson, A., TUC survey shows rise in psychosocial hazards at work, (2011), Retrieved on $4^{\text {th }}$ March 2017,

from https://www.eurofound.europa.eu/observatories/eurw ork/articles/tuc-surveyshows-rise-in-psychosocialhazards-at-work

[10]Australian Government Comcare, Psychosocial hazards, (2014), Retrieved on $24^{\text {th }}$ April 2017,from https://www.comcare.gov.au/preventing/hazards/psy chosocial_hazards

[11]European Agency for Safety and Health at Work, Psychosocial risks and stress at work - Safety and health at work, (2018), Retrieved on April 24, 2018, from https://osha.europa.eu/en/themes/psychosocialrisks-and-stress

[12] Ibrahim, N., Mutalib, F. L., \& Sari, S., Affecting factors of weight and gender on Carotid Arterial Wall Motion: Diameter and displacement assessment. International Journal of Integrated Engineering, Volume 9(3), (2017), pp.7 - 10.

[13] World Health Organisation (WHO), Obesity and overweight. WHO, (2018), Retrieved on $18^{\text {th }}$ May 2018 ,

from http://www.who.int/mediacentre/factsheets/fs311/en/

[14]Centre Disease Control (CDC), Defining adult overweight and obesity, (2016), Retrieved on $8^{\text {th }}$ March 2017, from https://www.cdc.gov/obesity/adult/defining.html

[15]NHS, Obesity - NHS choices, (2016), Retrieved on $17^{\text {th }} \quad$ May 2018, from http://www.nhs.uk/conditions/Obesity/Pages/Introdu ction.aspx

[16] World Health Organization (WHO), Promoting mental health: Concepts, emerging evidence, Practice: Summary Report, (2004), Retrieved on $25^{\text {th }}$ June 2018, from http://www.who.int/mental_health/evidence/en/prom oting_mhh.pdf

[17] Centre Disease Control (CDC), CDC - Mental health basics - Mental Health, (2011), Retrieved on $24^{\text {th }}$ April 2017, from https://www.cdc.gov/mentalhealth/basics.htm

[18] Mayo Clinic Staff, Mental illness - Mayo Clinic, (2015), Retrieved on 24 ${ }^{\text {th }}$ April 2017, from http://www.mayoclinic.org/diseasesconditions/mentalillness/basics/definition/con20033813

[19] Juliet Hassard, \& Tom Cox, Mental health at work, (2016), Retrieved on $3^{\text {rd }}$ June 2017, from https://oshwiki.eu/wiki/Mental_health_at_work

[20] Muntaner, C., Ng, E., Prins, S. J., Bones-Rocha, K., Espelt, A., \& Chung, H., Social class and mental health. International Journal of Health Services, Volume 45(2), (2015), pp. 265-284.

[21] Holden, S., \& Sunindijo, R. Y., Technology, long work hours, and stress worsen work-life balance in the construction industry. International Journal of Integrated Engineering, Volume 10(2), (2018), pp. $13-18$.

[22] Schulte, P. A., Wagner, G. R., Ostry, A., Blanciforti, L. A., Cutlip, R. G., Krajnak, K. M., Luster, M., Munson, A.E., O'Callaghan, J.P., Parks, C.G., Simeonova, P. P., \& Miller, D. B., Work, obesity, and occupational safety and health. American Journal of Public Health, Volume 97(3), (2007), pp. 428-36.

[23] Ghimire, U., Perceived stress and its association with psychosocial working conditions, (2014), Master Thesis, University of Eastern Finland.

[24]Hafner, M., Stolk, C. van, Saunders, C., Krapels, J., \& Baruch, B., Health, wellbeing and productivity in the workplace: A Britain's healthiest company 
summary report, (2015), Retrieved on $20^{\text {th }}$ May 2018, https://www.rand.org/pubs/research reports/RR1084. html

[25] Arlinghaus, A., Lombardi, D. A., Willetts, J. L., Folkard, S., \& Christiani, D. C., A structural equation modeling approach to fatigue-related risk factors for occupational injury. American Journal of Epidemiology, Volume 176(7), (2012), pp. 597-607.

[26]Kortum, E., Psychosocial risks and work- related stress in developing countries: a call for research and action in policy development, (2011), $\mathrm{PhD}$ thesis, University of Nottingham.

[27] Lundqvist, D., Psychosocial work conditions, health, and leadership of managers, (2013), Linköping University Medical Dissertations No. 1367.
[28]Labaree, R. V., Organizing your social sciences research paper: Quantitative Methods, (2010), Retrieved on $19^{\text {th }}$ June 2018, from http://libguides.usc.edu/writingguide/quantitative

[29] MSG, Secondary data - Meaning, its advantages and disadvantages, (2017), Retrieved on $26^{\text {th }}$ April 2017, from

http://www.managementstudyguide.com/secondary_ data.htm

[30]Krejcie, R. V, \& Morgan, D. W., Determining sample size for research activities. Educational and Psychological Measurement, Volume 38(1), (1970), pp. 607-610.

[31] George, D., \& Mallery, P., SPSS for Windows Step by Step A Simple Guide and Reference Answers to Selected Exercises, (2003), Boston: Align \& Bacon. 